
\section{列}

\title{
Silencing of an efflux pump coding gene decreases the efflux rate of pyrazinoic acid in Mycobacterium smegmatis
}

\author{
Stefany Quiñones-Garcia1, Robert H. Gilman², Patricia Sheen ${ }^{1}$, Mirko Zimic ${ }^{1 *}$
}

\footnotetext{
1'Laboratorio de Bioinformática y Biología Molecular. Laboratorios de Investigación y Desarrollo. Facultad de Ciencias y Filosofía. Universidad Peruana Cayetano Heredia, Lima, Peru.
}

2Department of International Health, Johns Hopkins Bloomberg School of Public Health, Baltimore, Maryland, USA.

*Corresponding author: Laboratorio de Bioinformática, Biología Molecular y Desarrollos Tecnológicos. Laboratorios de Investigación y Desarrollo. Facultad de Ciencias y Filosofía. Universidad Peruana Cayetano Heredia. Av. Honorio Delgado 430, SMP. Lima, Perú.

Email: mirko.zimic@upch.pe

\section{ABSTRACT}

Background: Tuberculosis (TB) is an infectious disease caused by Mycobacterium tuberculosis (MTB). The recommended treatment for TB is based on the use of first-line drugs, including pyrazinamide (PZA). PZA is also a drug used in the treatment of multidrugresistant TB (MDR-TB) because of its main effect against the latent stage. The main cause of resistance to PZA is mutations in the pncA gene, which compromise the activity of the encoded enzyme pyrazinamidase (PZAse), which hydrolyzes PZA into POA, the active antituberculosis molecule. The mechanism of action of PZA requires that POA is expelled from the bacterium by an efflux mechanism. After that, if the extracellular medium is sufficiently acidic, POA is protonated and returns to the cytosol, releasing the proton and repeating the cycle, resulting lethal to the bacteria. The efflux pump responsible for extruding the POA to the extracellular environment is not yet known. Mycobacterium smegmatis is naturally resistant to PZA and has a 900-fold faster POA efflux rate than MTB, and has the advantage to be a faster growing mycobacterium.

Methods: In the present study we have silenced the transcription of several genes encoding efflux pumps in $M$. smegmatis by CRISPRi (CRISPR interference). These genes 

homologous to efflux pump genes in MTB. POA efflux rate was measured, and a quantitative Wayne's test was performed after silencing each gene.

Results: Silencing of MSMEG_0250, resulted in approximately 5-fold decrease in the POA efflux rate in $M$. smegmatis $(\mathrm{P}<0.0001)$. None of the other silenced genes showed a notable decrease in POA efflux rate.

\section{KEY WORDS}

Pyrazinoic acid, efflux pump, pyrazinamide, efflux velocity, mechanism of action, drug resistance, Mycobacterium tuberculosis, Mycobacterium smegmatis, CRISPRi, silencing, transcription, tuberculosis, gene expression.

\section{INTRODUCTION}

Tuberculosis (TB) is an infectious disease caused by Mycobacterium tuberculosis (MTB) and is one of the 10 leading causes of death worldwide ${ }^{1,2}$. In 2019, 10000000 cases of people were reported to have developed the disease with an estimated 1200000 deaths ${ }^{1}$.

Pulmonary TB infection is transmitted when a patient with active TB coughs or sneezes, expelling small particles in the form of aerosols that contain MTB and easily penetrate the

51 respiratory tract $^{3,4}$. The treatment recommended by the World Health Organization (WHO)

52 to combat TB in adults is the use of first-line drugs (rifampicin, isoniazid, pyrazinamide, and

53 ethambutol). ${ }^{5}$. However, one of the main problems is multidrug-resistant TB (MDR-TB). ${ }^{1}$.

54 Pyrazinamide (PZA) is an important first-line drug used for the treatment of $\mathrm{TB}$ and the 55 eradication of latent strains ${ }^{6,7}$. PZA enters MTB by passive diffusion, is hydrolyzed to its 56 active form by the enzyme pyrazinamidase (PZAse), encoded by the pncA gene, to 57 pyrazinoic acid (POA). By means of an efflux mechanism, POA is released into the 58 extracellular environment, where it is protonated (HPOA), and then re-enters the bacterium 
assisted by a potential gradient, where it releases a proton $\left(\mathrm{H}^{+}\right)$acidifying the cytoplasm and repeating the cycle ${ }^{8-10}$.

Despite this understanding, the mechanism of action of PZA in MTB is not entirely clear. Neither the POA binding targets nor the efflux pumps responsible for transporting POA to the extracellular environment are known with certainty ${ }^{6,11}$. During the last decades, it has been identified that one of the main causes of resistance to PZA is mutations in the pncA gene, which encodes PZAse, causing functional alterations ${ }^{12-14}$. Not only mutations in pncA, but also mutations in the promoter, which cause under-expression of PZAse, are associated with resistance to $P Z A^{15}$.

PZA-resistant strains that do not lose full PZAsa activity, suggest the existence of other complementary resistance mechanisms, such as possibly mutations in POA/PZA-binding target proteins or mutations in the efflux pumps that expel POA ${ }^{13,16-19}$.

The mycobacterial cell wall, composed of mycolic acids, is a very efficient but permeable barrier that prevents the passage of some drugs into the intracellular environment of mycobacteria. However, the permeability characteristics do not explain the resistance to antituberculosis drugs ${ }^{18,20,21}$. Efflux pumps contribute to the expulsion of drugs to the extracellular environment, which decreases the concentration of drugs in the intracellular medium. Mutations in the efflux pump genes may limit the elimination of drugs from the intracellular medium and have been associated with bacterial resistance ${ }^{18,22,23}$. In the case of PZA, it has been observed that resistant strains have a low POA efflux rate, suggesting that POA efflux velocity could be a mechanism of study to identify efflux pumps related to the mechanisms of action and resistance to $\mathrm{PZA}^{24,25}$.

Recent studies have reported efflux pump genes that may be related to drug resistance, such as Rv1634 and Rv1250, which have been shown to decrease susceptibility to antibiotics when overexpressed in $\mathrm{MTB}^{26,27}$. Likewise, clinical strains of MTB that do not present mutations in PZAsa, but in the Rv1183 and Rv0202c genes, which encode the transmembrane transporter proteins MmpL10 and Mmpl11 respectively, show resistance to PZA, while the Rv0206c gene, which encodes the MmpL3 protein, has been reported as a target for binding to antituberculosis drugs ${ }^{28,29}$.

Mycobacterium smegmatis has similar characteristics to $M$. tuberculosis, although it is not pathogenic, is faster growing and is naturally resistant to PZA. Therefore, M. smegmatis constitutes an appropriate model to study anti-tuberculosis drugs ${ }^{30,31}$. 
91 In the present work, we silenced homologous MTB genes in M. smegmatis, MSMEG_0250,

92 MSMEG_3815, MSMEG_0241, MSMEG 0410, and MSMEG_5046 was performed by

93 CRISPRi. The silenced strains were evaluated to measure the change in POA efflux velocity

94 in M. smegmatis.

95

96

97 METHODOLOGY

98 Bacterial strain

99 All M. smegmatis strains generated in this study are derived from reference strain $\mathrm{mc}^{2} 155$

100 and Escherichia coli from Nova Blue.

\section{Culture media}

102 E. coli strains were grown on Luria-Bertani (LB) medium at $37^{\circ} \mathrm{C}$. M. smegmatis strains were 103 grown in $7 \mathrm{H} 9$ broth, and $7 \mathrm{H} 10$ media on plates supplemented with $0.2 \%$ de glycerol, $0.05 \%$ 104 Tween 80, and 10\% Oleic Albumin Dextrose Catalase (OADC). The antibiotics kanamycin $105(20 \mu \mathrm{g} / \mu \mathrm{l})$ and carbenicillin $(50 \mu \mathrm{g} / \mu \mathrm{l})$ was used for $M$. smegmatis and $E$. coli cultures 106 recombinant with pLJR962 plasmid.

107 Growth of mycobacteria

108 M. smegmatis clones with and without the pLJR962 plasmids with the cloned gRNAs were 109 cultured in $10 \mathrm{ml}$ of $7 \mathrm{H} 9$ broth with kanamycin $(20 \mu \mathrm{g} / \mu \mathrm{l})$ and carbenicillin $(50 \mu \mathrm{g} / \mathrm{ml})$ at $37^{\circ} \mathrm{C}$ 110 at 300 rpm for 3 - 5 days. From this culture was inoculated in a new 7H9 broth with 111 kanamycin $(20 \mu \mathrm{g} / \mu \mathrm{l})$ and carbenicillin $(50 \mu \mathrm{g} / \mathrm{ml})$ at $37^{\circ} \mathrm{C}$ at $300 \mathrm{rpm}$ for 18 hours, until 112 reaching its logarithmic phase, $\mathrm{OD}_{600 \mathrm{~nm}}: 0.5-0.8$. It was then diluted with a $7 \mathrm{H} 9$ medium 113 until its $\mathrm{OD}_{600 \mathrm{~nm}}$ was $0.1-0.2$ to induce the CRISPRi system. 
120 MTB genes reported to encode efflux pumps (Rv1634, Rv0202c, Rv1183, Rv1250, and $121 R v 0206 c)$, were used to identify the homologous genes in M. smegmatis, using the Basic 122 Local Alignment Search Tool - NCBI (BLAST) ${ }^{32}$, with an identity filter greater than $50 \%$.

\section{Design and cloning of guide RNAs (RNAg)}

124 Based on the homologous genes in M. smegmatis (MSMEG_0250, MSMEG_3815, and 125 MSMEG_0241), an RNAg was designed for each according to the protocol described by 126 Rock ${ }^{33,34}$. Specifically, two RNAg were designed for each of the MSMEG_5046 (gRNA1 and 127 gRNA2) and MSMEG_0410 (gRNA1 and gRNA2) genes.

128 The gRNAs were cloned into the plasmid pLJR962 having the dCas9 $9_{\text {spy }}$ system, with the 129 restriction enzyme BsmBI (New England) and into E. coli Nova blue. The plasmids were 130 then extracted, and cloning was confirmed by sanger sequencing at MACROGEN (USA) 131 and transformed by electroporation into M. smegmatis.

\section{Transcriptional Repression of Genes by CRISPRi}

133 Co-expression of dCas9spy was induced with the gRNAs of each gene in M. smegmatis 134 strains with $100 \mathrm{ng} / \mathrm{mL}$ ATc, which were incubated for $14-24$ hours at $37^{\circ} \mathrm{C}, 300 \mathrm{rpm}$ until 135 reaching an $\mathrm{OD}_{600 \mathrm{~nm}}$ greater than 1 . In addition, as a control for each gene, we evaluated 136 the recombinant bacteria with the CRISPRi system with no ATc added.

138 Mycobacterium was induced and not induced with ATc were centrifugate mRNA 139 quantification in a $15 \mathrm{~mL}$ RNase and DNase free tube at $12500 \mathrm{rpm}$ for $20 \mathrm{~min}$ at $4^{\circ} \mathrm{C}$, then 140 the pellet was washed with TE buffer pH8 at $12500 \mathrm{rpm}$ for $20 \mathrm{~min}$ at $4^{\circ} \mathrm{C}$ and resuspended 141 in $1 \mathrm{~mL}$ of TRI Reagent (Zymo Research) in a screw-cap tube with $0.1 \mathrm{~mm}$ zirconia beads. 142 Cells were lysed at $6.5 \mathrm{~m} / \mathrm{s}$ for 30 seconds, twice, with an interval of three minutes for each 143 cycle in the Fast Prep equipment (MP Biomedicals) and RNA was extracted with Directzol 144 RNA kit columns (Zymo Research). The extracted RNA was treated with Ambion DNasel 145 (Thermo Fisher Scientific), and a DNA strand was formed with the SuperScript IV retro 146 transcriptase kit (Thermo Fisher Scientific). Quantification of the mRNA concentration of the 147 gene of interest with respect to the constitutively expressed gene MSMEG_2758, which 148 encodes sigma factor, was performed by qPCR-RT following the published $\Delta \Delta \mathrm{Ct}$ protocol ${ }^{35}$, 
with SYBR Green (Takara) and with specific primers for each of them ${ }^{33}$. Primers were designed in NCBI primer-blast software, placed after the gRNAs of each sequence.

\section{Measurement of POA efflux rate}

POA efflux velocity of mycobacteria with the silenced genes was measured following the previously standardized protocol and POA quantification was normalized to Bradford (POA $\mathrm{mg} /$ protein) ${ }^{24,25}$. Briefly, mycobacterial growth and transcriptional repression of genes were performed in $17 \mathrm{~mL}$ of $7 \mathrm{H} 9$ medium. These were centrifuged at $12500 \mathrm{rpm}$ for $20 \mathrm{~min}$ at $4^{\circ} \mathrm{C}$, the pellet was resuspended with $10 \mathrm{mM}$ citrate buffer $\mathrm{pH} 7$ until their $\mathrm{OD}_{600 \mathrm{~nm}}$ of ATctreated and untreated mycobacteria were adjusted equally. From the pellet suspension, 900 $\mu \mathrm{L}$ aliquots were made and tempered at $37^{\circ} \mathrm{C}$ for $20 \mathrm{~min}$, then $100 \mu \mathrm{L}$ of $10 \mathrm{mM}$ PZA (Sigma Aldrich) was added and the mixture was incubated at $37^{\circ} \mathrm{C}$ at different time intervals 5,10 , $15,15,20,20,25$ and $30 \mathrm{~min}$. The reaction was stopped by centrifugation at $14800 \mathrm{rpm}$ for 2 min, of which $500 \mu \mathrm{L}$ of the supernatant, extracellular fraction, was saved for the Wayne reaction at $450 \mathrm{~nm}$. The control, time 0 , was $450 \mu \mathrm{L}$ of supernatant without incubation with $50 \mu \mathrm{L}$ of $10 \mathrm{mM}$ PZA. Pellets from the reactions were resuspended with $500 \mu \mathrm{L}$ of $10 \mathrm{mM}$ citrate buffer at $\mathrm{pH} 7$, cells were lysed at $100{ }^{\circ} \mathrm{C}$ for $20 \mathrm{~min}$, and centrifuged at $10000 \mathrm{rpm}$ for $10 \mathrm{~min}$. The supernatants were used to quantify lysate proteins by Bradford (Bio Rad).

\section{Data analysis}

POA efflux rate was estimated by linear regression of POA concentration at times $0,5,10$, 15, 15, 20, 25, and 30 min. To compare efflux velocities between CRISPRi-silenced and CRISPRi-non-silenced bacteria, multiple linear regression was used including an interaction term between time and an indicator variable $(0 / 1)$ that accounts for whether CRISPRi was or was not induced. Analyses were performed at $5 \%$ significance using Stata statistical software version 14 (Stata Corp., College Station, TX). 


\section{RESULTS}

\section{MTB genes in M. smegmatis}

181 Genes Rv1634, Rv0202c, Rv1183, Rv1250, and Rv0206c, homologous MTB genes in $M$. 182 smegmatis with greater than 50\% identity were identified, MSMEG_3815, MSMEG_0241, 183 MSMEG_0410,MSMEG_5046, and MSMEG_0250 respectively.

185 Three qPCR repeats of the strains ATc-treated and untreated CRISPRi strains, showed 186 notable variations of the transcription level. 100-1000 folds changes were observed (Figure 187 1).

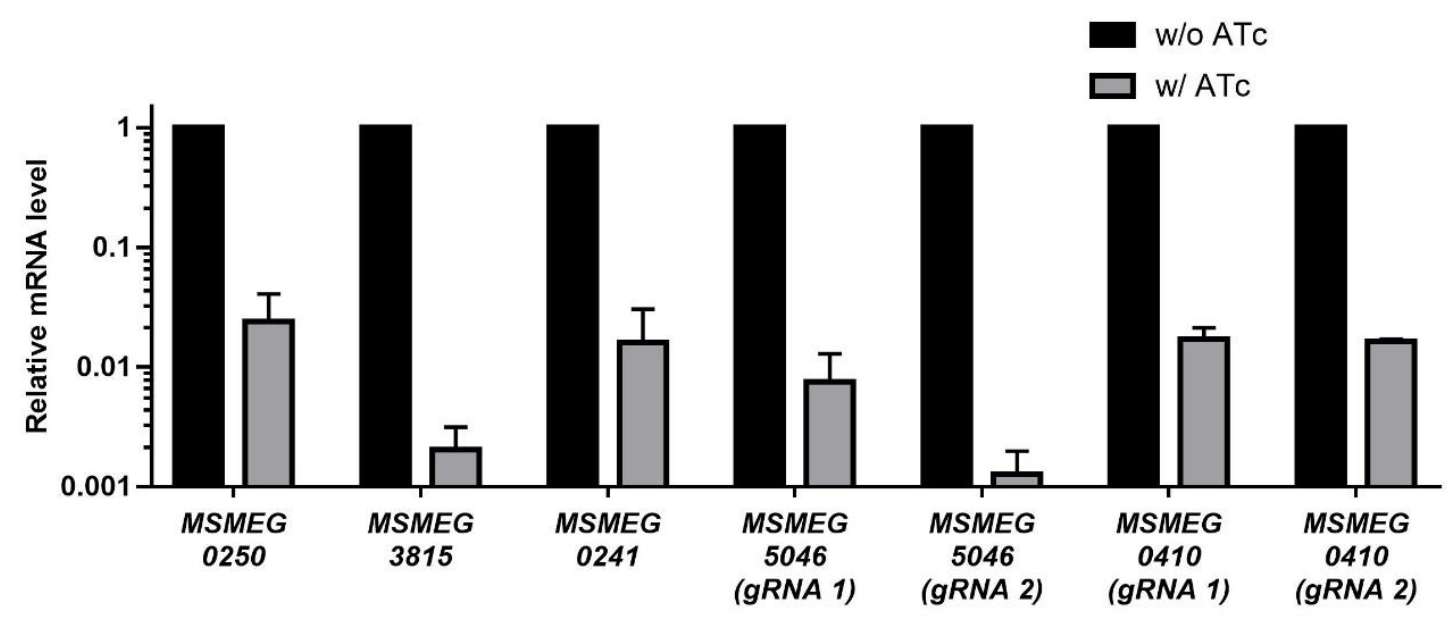

Figure 1: Plot of the difference of $\mathrm{dCas} 9_{\mathrm{sth} 1}$ co-expression with MSMEG_0250, 191 MSMEG_3815, MSMEG_0241, MSMEG_5046 (gRNA 1 and gRNA2) and MSMEG_0410 192 (gRNA 1 and gRNA2) genes by relative mRNA quantification, showing difference between 193 bacteria with silenced, ATc treated, and unsilenced genes, without ATc. 95\% confidence 194 intervals are shown. 


\section{genes}

200 The only gene that showed a noticeable and significant change in POA efflux velocity when

201 CRISPRi was activated was the MSMEG_0250 gene $(p=0.000)$. The POA efflux rate without 202 silencing $(797 \mathrm{mM} / \mathrm{s})$ was reduced 5 -fold $(162.8 \mathrm{mM} / \mathrm{s})$. Although not significant, in 203 MSMEG_0241 and MSMEG_5046 (gRNA 1) genes, a trend of a decrease in efflux velocity 204 was observed in 1.4 and 1.6 folds respectively (Figure 2).
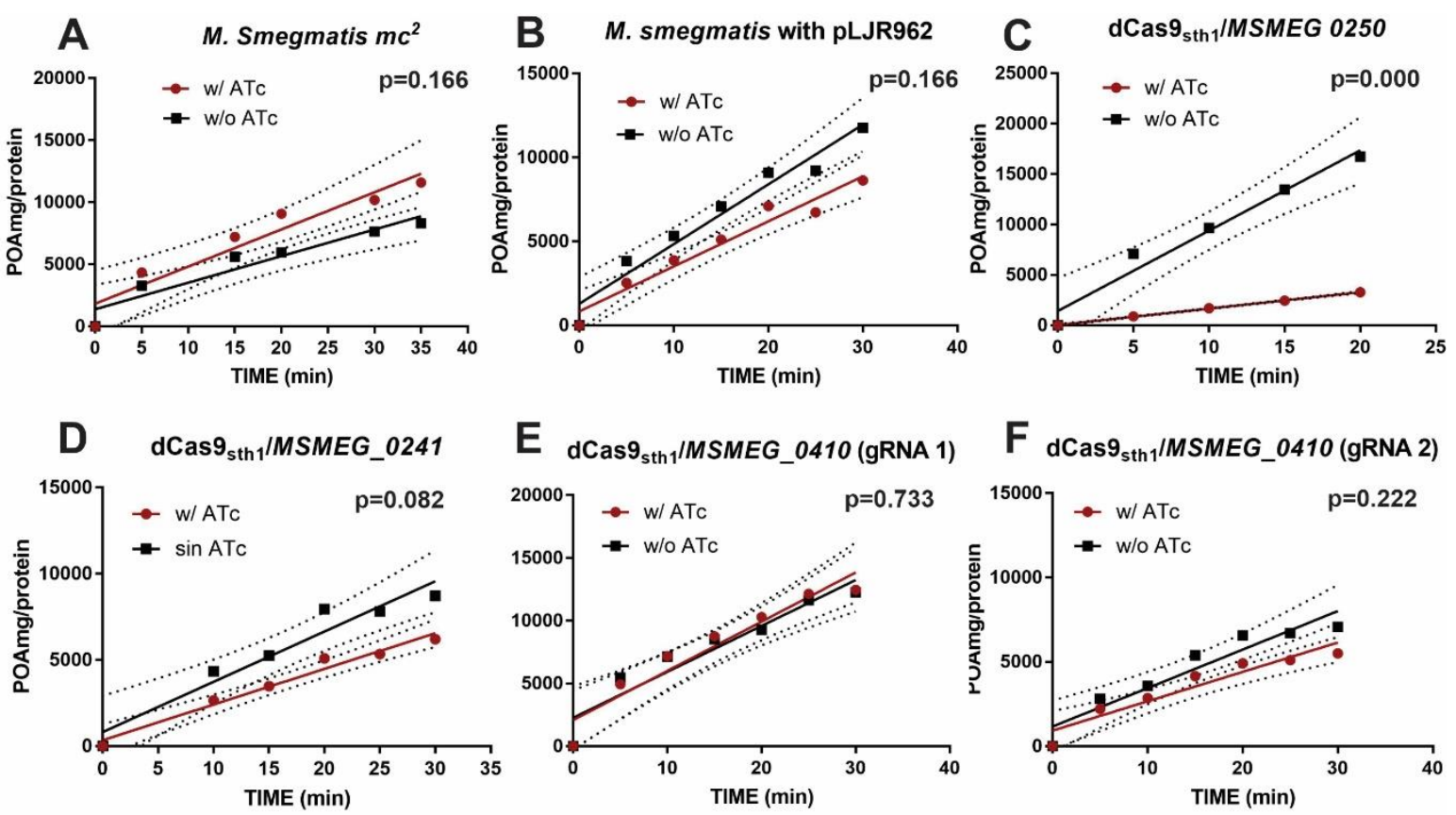

$F_{\text {dCas9 }}$ sth $1 M S M E G_{-} 0410$ (gRNA 2)
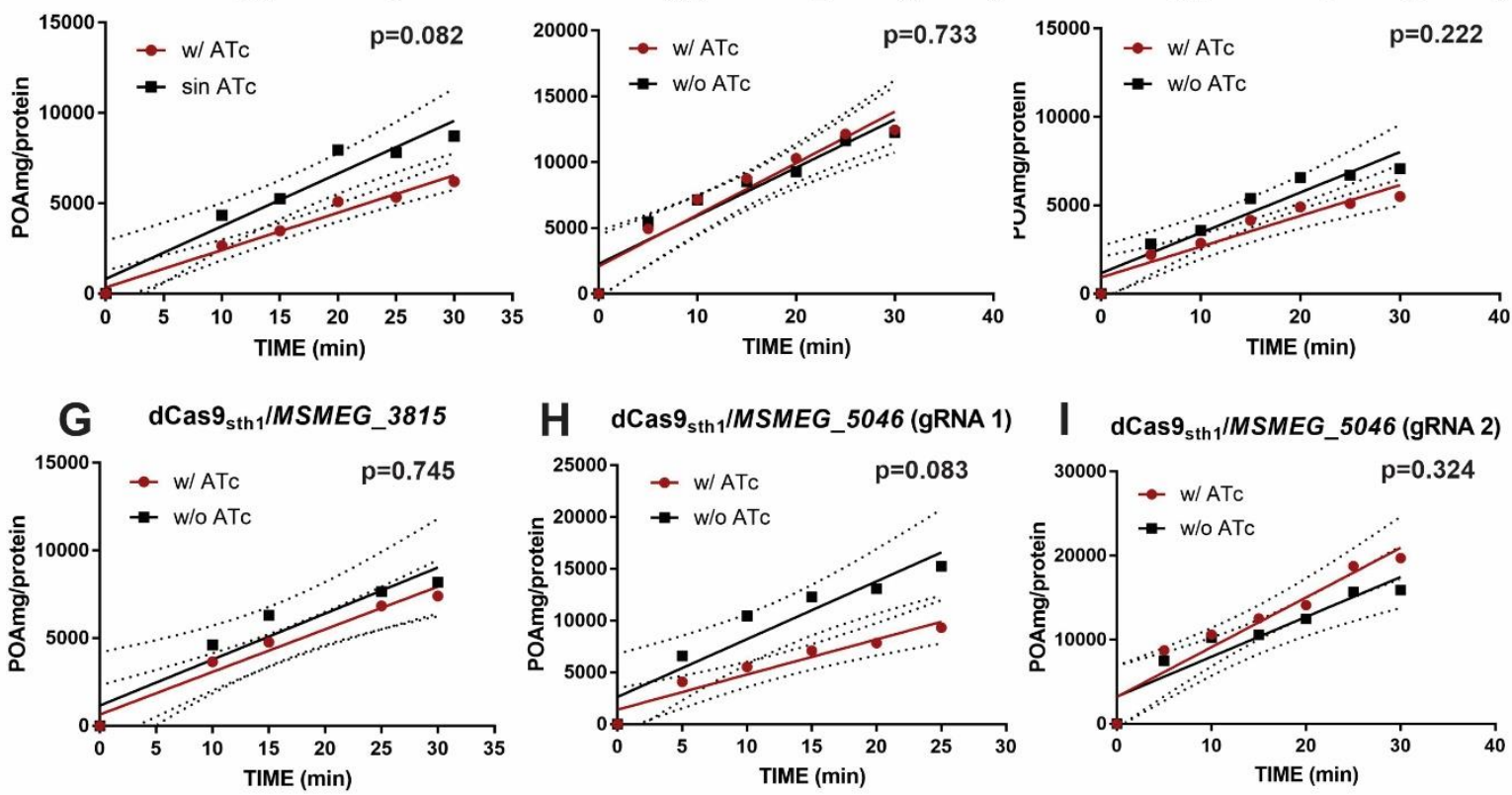

Figure 2: Measurement of POA efflux velocity in $M$. smegmatis when a gene is silenced with the CRISPRi system, induced with ATc and unsilenced, without ATc. (A) Control 1, M. smegmatis, no significant change in efflux velocity $(\mathrm{P}=0.166)$, $(\mathrm{B})$ Control 2, M. smegmatis with plasmid pLJR962, no significant change in efflux velocity ( $P=0$. 166), (C) Gene 
212 unsilenced ( $P=0.000)$, (D) Gene MSMEG_3815, shows no significant difference in efflux 213 velocity ( $P=0.745)$, (E) Gene MSMEG_5046 (gRNA 1), shows no significant difference in 214 efflux velocity ( $\mathrm{P}=0.083)$, (F) Gene MSMEG_5046 (gRNA 2), shows no significant difference 215 in efflux velocity ( $P=0.324)$, (G) Gene MSMEG_0241, shows no significant difference in 216 efflux velocity ( $\mathrm{P}=0$. 082), (H) Gene MSMEG_0410 (gRNA 1), shows no significant 217 difference in efflux velocity $(\mathrm{P}=0.733)$ and (I) Gene MSMEG_0410 (gRNA 2), shows no 218 significant difference in efflux velocity $(\mathrm{P}=0.222) .95 \%$ confidence intervals are shown.

\section{DISCUSION}

222 POA efflux velocity in $M$. smegmatis is markedly and significantly reduced when the 223 MSMEG_0250 gene is silenced by CRISPRi $(p<0.001)$. Although not significantly, other 224 genes also silenced are found to be associated with a trend of decreased POA efflux 225 velocity.

226 Efflux pumps are responsible for generating the expulsion of drugs into the extracellular 227 medium of the bacteria ${ }^{6,9,10,24,25}$. In previous works, we have observed that the rate of POA 228 efflux into the extracellular medium has a wide range of variation, and thus possibly occurs 229 through an active transport mechanism mediated by some efflux pumps (unpublished data).

230 Typically, PZA-resistant strains tend to have a very low POA efflux rate; however, it has also 231 been reported that PZA-resistant strains can have very high POA efflux rates. It appears 232 that PZA-susceptible strains are associated with an intermediate range of POA efflux 233 velocities ${ }^{24}$.

234 The MSMEG_0250 gene, which encodes the MmpL3 protein, is an essential gene under in 235 vitro conditions in mycobacteria and transporter of mycolic acid in the form of trehalose 236 monomycolates (TMM) from the cytoplasm to the cell wall ${ }^{28,36,37}$. Additionally, it is a complex 237 bound to the TMM transport factor A (TtfA) protein, encoded by gene 0736 and to the 238 MSMEG_5308 gene. The first two complexes are exclusively responsible for TMM transport, 239 while MSMEG_5308, upon Mmpl3 depletion, accumulates and stabilizes the Mmpl3/TtfA 240 complex, preserving TMM transport and cell wall biosynthesis ${ }^{38}$.

241 The phenotypic evaluation shows that bacterial growth of $M$. smegmatis with the 242 MSMEG_0250 gene silenced by CRISPRi decreases on a 7H10 agar medium. This is not 
243

244

245

246

247

248

249

250

251

252

253

254

255

256

257

258

259

260

261

262

263

264

265

266

267

268

269

270

271

272

273

reproduced in $7 \mathrm{H} 9$ broth, where $M$. smegmatis grows in both silencing and non-silencing conditions. It is important to note that the liquid 7H9 medium allows mycobacteria to grow faster compared to the solid $7 \mathrm{H} 10$ medium $^{39}$. This could explain the difference in growth in both media. In the relative quantification of transcripts (mRNA) of the MSMEG_0250 gene, the decrease in expression under silencing conditions is partial with a $\mathrm{Cq}$ no greater than 30. It is possible that repression of the MSMEG_0250 gene is not sufficient to limit bacterial growth even though it is a highly vulnerable gene ${ }^{33,40-42}$. It is also possible that the partial loss of its function could be being compensated by other efflux pumps.

The vulnerability level of a gene is a measure of how essential it is. A highly vulnerable gene negatively affects the fitness of the bacterium and its growth ${ }^{42}$. The MSMEG_0250 gene, in addition to having been reported as an essential gene, has recently been shown that both MSMEG_0250 and its homolog RV0206c in MTB have a high vulnerability, and its silencing reduces bacterial growth ${ }^{42,43}$. For this reason, we believe that the observed decrease in POA efflux velocity following MSMEG_0250 gene silencing could potentially be due to loss of cell fitness. Further studies are needed to clarify this possibility.

Previous studies have shown that mutations in the MSMEG_0250 gene decrease the hydrophobicity of the bacterial cell wall ${ }^{28,44}$. It is possible that a partial silencing of this gene could contribute to the change in the efflux velocity of POA, POA is a hydrophilic molecule ${ }^{45}$.

Also, recent studies based on the use of CRISPRi dCas $9_{\text {sth } 1}$ for the silencing of the gene homologous to MSMEG_0250 in MTB, Rv0206c which encodes an efflux pump, have confirmed that this is a binding target for anti-TB drugs and can be used as an anti-TB drug discovery system ${ }^{46,47}$.

Inhibition of MSMEG_0250 expression by CRISPRi could potentially affect the expression of more genes if they are associated with an operon ${ }^{48}$, especially if they are in the $5^{\prime}$ region of the gene of interest ${ }^{33,49,50}$. However, recent studies have shown that the MSMEG_0250 gene does not share an operon with other genes, suggesting that the effect of silencing on POA efflux velocity would be a direct effect of the MSMEG_0250 gene ${ }^{42}$.

During the evaluation of bacterial growth, no variation of bacterial growth was observed between mycobacteria silenced and non-silenced in the $7 \mathrm{H} 9$ culture medium. This confirms previous findings that ATc is not toxic to mycobacteria and would not be influencing the variation of POA efflux velocity ${ }^{25,51}$. 
274 ATc is a tetracycline derivative, an efficient inducer of the TetR repression promoter, which

275 does not affect bacterial growth in Mycobacterium ${ }^{33,51,52}$. The optimal concentrations of ATc

276 as an inducer for TetR in mycobacteria are from 50 to $100 \mathrm{ng} / \mathrm{mL}$. At concentrations higher

277 than 250 or $500 \mathrm{ng} / \mathrm{mL}$, the inducer reduces its activity on the TetR promoter, decreasing

278 the fold repression of silenced genes and increasing bacterial growth in essential 279 genes $^{33,51,52}$.

280 Although silencing of the MSMEG_0410 and MSMEG_5046 genes was performed with two 281 different gRNA and different PAM sequences, which generated different repression folds, 282 no significant variation of POA efflux velocity was detected $(p>0.001)$. This strongly suggests 283 that none of these efflux pumps would be involved in POA transport.

284 Although there are other systems for silencing mycobacterial genes and evaluating their 285 effect on the rate of POA efflux, such as homologous recombination knock-out, it is important 286 to recognize the advantage of using CRISPRi, since it is possible to control the level of 287 repression of gene expression and thus avoid reaching extreme levels of total absence of 288 expression ${ }^{43,46,50,53}$. Additionally, the CRISPRi system standardized by Rock et al. 2017, is 289 easy and fast to manipulate. Thanks to the knowledge of PAM sequences and the different 290 repression folds, it is simple to design a gRNA for a sequence of interest ${ }^{33}$.

291 Possible effects of MSMEG_0250 gene silencing could be studied at the transcriptomic 292 sequencing level, and thus determine which other genes could alter its expression, possibly 293 in a compensatory manner, in particular genes associated with efflux pumps or genes 294 affecting bacterial fitness ${ }^{54,55}$. Likewise, the vulnerability of MSMEG_0250 could be analyzed 295 through a knock-out by homologous recombination, generating the most extreme scenario 296 associated with a complete absence of expression.

297 In conclusion, silencing of the MSMEG_0250 gene results in a significant 5-fold decrease in 298 POA efflux velocity in M. smegmatis, so this gene could be involved in active POA transport.

\section{ACKNOWLEDGEMENTS}

301 We thank Dr. Jeremy Rocks for his generous support in providing us with the technology to 302 perform the CRISPRi technique. 


\section{REFERENCES}

305 1. World Health Organization. Global Tuberculosis Report 2020. (2020).

$3062 . \quad$ Wolrd Health Organization. Global Tuberculosis Report 2019. (2019).

307 3. Ahmad, S. Pathogenesis, immunology, and diagnosis of latent Mycobacterium 308 tuberculosis infection. Clinical and Developmental Immunology 2011, 17 (2011).

309 4. Goodman, J. Mycobacterium tuberculosis invades and replicates within type II alveolar cells. These include: Mycobacterium tuberculosis Invades and Replicates within Type II Alveolar Cells. 64, 1400-1406 (1996).

312 5. World Health Organization. Treatment of tuberculosis: guidelines. 4Th Edition 160 (2010).

6. Zhang, Y. \& Mitchison, D. The curious characteristics of pyrazinamide: A review. International Journal of Tuberculosis and Lung Disease 7, 6-21 (2003).

316 7. Suzuki, Y., Suzuki, A., Tamaru, A., Katsukawa, C. \& Oda, H. Rapid Detection of

8. Frothingham, R., Meeker-O'Connell, W. A., Talbot, E. A. S., George, J. W. \& Kreuzer,

9. Zhang, Y., Shi, W., Zhang, W. \& Mitchison, D. Mechanisms of pyrazinamide action and nicotinamidase gene, pnc A. Antimicrobial Agents and Chemotherapy 40, 14261431 (1996).

10. Stehr, M., Elamin, A. A. \& Singh, M. Pyrazinamide: The importance of uncovering the

11. Cole, S. T. Pyrazinamide-Old TB Drug Finds New Target. Science 333, 1583-1584 (2011).

12. Sheen, P. et al. Effect of pyrazinamidase activity on pyrazinamide resistance in Mycobacterium tuberculosis. Tuberculosis 89, 109-113 (2009). 
Resistance 6, 283-7 (2000).

14. Petrella, S. et al. Crystal structure of the pyrazinamidase of mycobacterium tuberculosis: Insights into natural and acquired resistance to pyrazinamide. PLoS ONE 6, (2011).

15. Sheen, P. et al. pncA gene expression and prediction factors on pyrazinamide resistance in Mycobacterium tuberculosis. Tuberculosis 93, 515-522 (2013).

16. Yang, J. et al. Structural basis for targeting the ribosomal protein $S 1$ of Mycobacterium tuberculosis by pyrazinamide. Molecular Microbiology 95, (2015).

17. Kanji, A., Hasan, R. \& Hasan, Z. Efflux pump as alternate mechanism for drug resistance in Mycobacterium tuberculosis. Elsevier science 66, 20-25 (2018).

18. Te Brake, L. H. M. et al. The Role of Efflux Pumps in Tuberculosis Treatment and Their Promise as a Target in Drug Development: Unraveling the Black Box. Annual Review of Pharmacology and Toxicology 58, (2018).

19. Zimhony, O., Cox, J. S., Welch, J. T., Vilchèze, C. \& Jacobs, W. R. Pyrazinamide inhibits the eukaryotic-like fatty acid synthetase I (FASI) of Mycobacterium tuberculosis. Nature medicine 6, 1043-1047 (2000).

20. Szumowski, J. D., Adams, K. N., Edelstein, P. H. \& Ramakrishnan, L. Antimicrobial efflux pumps and Mycobacterium tuberculosis drug tolerance: Evolutionary Considerations. Curr Top Microbiol Immunol. 6, 23-27 (2013).

21. Nikaido, H., Kim, S. \& Rosenberg, E. Y. Physical organization of lipids in the cell wall of Mycobacterium chelonae. Molecular Microbiology 8, 1025-1030 (1993).

22. Marquez, B. Bacterial efflux systems and efflux pumps inhibitors. Biochimie 87, 11371147 (2005).

23. da Silva, P. E. A., Groll, A. Von, Martin, A. \& Palomino, J. C. Efflux as a mechanism for drug resistance in Mycobacterium tuberculosis. Immunology and Medical Microbiology 63, 1-9 (2011).

24. Zimic, M. et al. Pyrazinoic acid efflux rate in Mycobacterium tuberculosis is a better proxy of pyrazinamide resistance. Tuberculosis 92, 84-91 (2012).

25. Zimic, M., Loli, S. \& Gilman, R. H. A New Approach for Pyrazinamide Susceptibility 
26. AlMatar, M., Var, I., Kayar, B. \& Köksal, F. Differential Expression of Resistant and Efflux Pump Genes in MDR-TB Isolates. Endocrine, Metabolic \& Immune Disorders Drug Targets 20, 271-287 (2019).

27. Kardan-Yamchi, J. et al. Expression analysis of 10 efflux pump genes in multidrugresistant and extensively drug-resistant Mycobacterium tuberculosis clinical isolates. Journal of Global Antimicrobial Resistance 17, 201-208 (2019).

28. Li, W. et al. MmpL3 as a target for the treatment of drug-resistant nontuberculous mycobacterial infections. 9, 1-9 (2018).

29. Sheen, P. et al. A multiple genome analysis of Mycobacterium tuberculosis reveals specific novel genes and mutations associated with pyrazinamide resistance. BMC Genomics 18, 769 (2017).

30. Tyagi, J. S. \& Sharma, D. Mycobacterium smegmatis and tuberculosis. Trends in Microbiology 10, 68-69 (2002).

32. Altschup, S. F., Gish, W., Miller, W., Myers, E. W. \& Lipman, D. J. Basic Local

31. Malhotra, S., Vedithi, S. C. \& Blundell, T. L. Decoding the similarities and differences Alignment Search Tool. Journal of Molecular Biology 215, 403-410 (1990).

33. Rock, J. M. et al. Programmable transcriptional repression in mycobacteria using an orthogonal CRISPR interference platform. Nature Microbiology 2, 1-9 (2017).

34. Wong, A. I. \& Rock, J. M. CRISPR interference (CRISPRi) for targeted gene silencing in micobacteria. The RoutledgeFalmer Reader in Higher Education 2314, (2021).

35. Livak, K. J. \& Schmittgen, T. D. Analysis of relative gene expression data using realtime quantitative PCR and the 2- $\triangle \triangle C T$ method. Methods 25, 402-408 (2001).

36. Xu, Z., Meshcheryakov, V. A., Poce, G. \& Chng, S. MmpL3 is the flippase for mycolic

37. Varela, C. et al. MmpL genes are associated with mycolic acid metabolism in Mycobacteria and Corynebacteria. Chemistry \& Biology 19, 498-506 (2012). 
mycobacteria. American Society for Microbiology 10, 1-17 (2019).

392

393

394

395

396

397

398

399

400

401

402

403

404

405

406

407

408

409

410

411

412

413

414

415

416

39. Moore, D. A. J. et al. Microscopic-observation drug-susceptibility assay for the diagnosis of TB. New England Journal of Medicine 355, 1539-1550 (2007).

40. Meijers, A. S. et al. Efficient genome editing in pathogenic mycobacteria using Streptococcus thermophilus CRISPR1-Cas9. Tuberculosis 124, 101983 (2020).

41. Houdebine, L. M. Design of Vectors for Optimizing Transgene Expression. Transgenic Animal Technology: A Laboratory Handbook: Third Edition (Elsevier Inc., 2014).

42. Bosch, B. et al. Genome-wide gene expression tuning reveals diverse vulnerabilities of M. tuberculosis. Cell 184, 4579-4592.e24 (2021).

43. Degiacomi, G. et al. Essentiality of $\mathrm{mmpL3}$ and impact of its silencing on Mycobacterium tuberculosis gene expression. Scientific Reports 7, 1-8 (2017).

44. Mcneil, M. B., Dennison, D. \& Parish, T. Mutations in MmpL3 alter membrane potential, hydrophobicity and antibiotic susceptibility in Mycobacterium smegmatis. Microbiology 163, 1065-1070 (2017).

45. Cynamon, M. H., Klemens, S. P., Chou, T., Gimi, R. H. \& Welch, J. T. Antimycobacterial Activity of a Series of Pyrazinoic Acid Esters. American Chemical Society 35, 1212-1215 (1992).

46. Mcneil, M. B. \& Cook, G. M. Utilization of CRISPR interference yo validate MmpL3 as a drug target in Mycobacterium tuberculosis. Antimicrobial Agents and Chemotherapy 63, 1-7 (2019).

47. Rock, J. Tuberculosis drug discovery in the CRISPR era. PLoS Pathogens 15, 1-10 (2019).

48. Singh, A. K. et al. Investigating essential gene function in Mycobacterium tuberculosis using an efficient CRISPR interference system. Nucleic acids research 44, (2016).

49. Choudhary, E., Thakur, P., Pareek, M. \& Agarwal, N. Gene silencing by CRISPR interference in mycobacteria. Nature Communications 6, 1-11 (2015).

50. Qi, L. S. et al. Repurposing CRISPR as an RNA-Guided Platform for SequenceSpecific Control of Gene Expression. Cell 152, 1173-1183 (2013). 
420 51. Ehrt, S. et al. Controlling gene expression in mycobacteria with anhydrotetracycline 421 and Tet repressor. Nucleic acids research 33, 1-11 (2005).

422 52. Gossen, M. \& Bujard, H. Anhydrotetracycline, a novel effector for tetracycline 423 controlled gene expression systems in eukaryotic cells. Nucleic Acids Research 21, $424 \quad 4411-4412(1993)$.

425 53. Zhang, B. et al. Crystal Structures of Membrane Transporter MmpL3, an Anti-TB Drug $426 \quad$ Target. Cell 176, 636-648.e13 (2019).

427 54. Podnar, J., Deiderick, H., Huerta, G. \& Hunicke-Smith, S. Next-generation 428 sequencing RNA-Seq library construction. Current Protocols in Molecular Biology 1$429 \quad 19(2014)$.

430 55. illumina. TruSeq Stranded mRNA. TruSeq Stranded mRNA Reference Guide 13, 431 258-262 (2017). 